\author{
RAUDHAH Proud To Be Profesional Jurnal Tarbiyah \\ Islamiyah Volume 5 Nomor Edisi 1 Juni 2020 \\ P-Issn :2541:3686
}

\title{
KONSEP PENDIDIKAN ISLAM “HUMAN TOUCH” MENURUT MUHAMMAD MUHAMMAD BADRI
}

\author{
Fitri Susanty \\ Sekolah Tinggi Ilmu Tarbiyah Raudhatul Ulum \\ Email: fitrisusanty@stit-ru.ac.id
}

\begin{abstract}
Abstrak
Banyak sekali kita temukan buku-buku, berbagai artikel bahkan sampai pada seminar-seminar yang membicarakan tentang pendidikan anak terutama konsep pendidikan Islam, namun hal tersebut masih berupa tataran teoritis saja. Maka, seorang dosen dalam bidamg Psikologi dan parenting anak menuangkan suatu konsep pendidikan Islam yang disebut "Human Touch" dimana konsep ini dibuat berdasarkan pengalaman dirinya ataupun orang lain dalam membesarkan buah hati tercinta. Konsep ini juga pastinya merujuk kepada Al-Qur'an dan Hadits nabi yang menggambarkan bagaimana seharusnya kita sebagai pendidik dan orang tua bersikap. Untuk melahirkan generasi Islam yang sholeh dan mushlih dalam hal medidik mereka harus punya banyak bekal, pengalaman dan ilmu. Kata-kata yang membentuk frase "Human Touch" inilah yang memberikan gambaran pengalaman dalam membentuk generasi yang dibutuhkan oleh umat Islam. Selain mengajarkan seni dalam mendidik, konsep ini mengingatkan para orang tua tentang tujuan mendidik anak. Kemudian memaparkan sarana apa saja yang bisa digunakan untuk mencapai tujuan itu.
\end{abstract}

Kata Kunci: pendidikan, Islam, Human Touch, Dr. Muhammad Muhammad Badri 


\section{Pendahuluan}

Pendidikan adalah suatu sarana untuk menciptakan insan manusia yang bermanfaat, cerdas dan bisa menyelesaikan berbagai permasalahan dalam kehidupan . Seseorang mendefinisikan pendidikan sebagai kerja keras para bapak bangsa dan guru bangsa untuk mencetak generasi masa depan berlandaskan pandangan hidup yang mereka yakin ${ }^{1}$. John F. Kennedy mengatakan bahwa "Tujuan pendidikan adalah kemajuan pengetahuan dan penyebaran kebenaran.

Jadi, apa tujuan pendidikan kita? Dan, seperti apa generasi yang kita idamkan?. Semua system pendidikan di dunia, baik Timur maupun Barat, memiliki satu tujuan yang sama, yaitu menyiapkan anak bangsa yang berkualitas, namun masing-masing berbeda dalam hal kemasan dan warnanya.

Ukuran kualitas masing-masing anak bangsa sangat berbeda satu sama lain, tergantung selera para pendidiknya, mengikuti paham-paham sempit kebangsaan yang membatasinya. Sedangkan Islam sama sekali berbeda dari system itu dalam memandang keutaamaan dan tujuan. Perihal mana yang dianggap utama, Islam tidak membatasi dirinya dengan wawasan sempit para pendidik itu, sehingga sejak awal Islam tidak berusaha menyiapkan"anak bangsa yang berkualitas", melainkan sejak awal hingga akhir berusaha mencapai tujuan yang jauh lebih luhur, lebih besar, dan lebih sempurna, yakni menyiapakan insane yang shalih. Sebab misi Islam adalah misi kemanusiaan, bukan misi kebangsaan; sebuah misi yang selaras dengan kemanusiaan insane. Pendidikan Islam bahkan melampaui tujuan itu untuk mencapai tujuan yang lebih luhur lagi, yakni menyiapkan "insan yang mushlih" yang bias menduplikasikan keshalihannya kepada generasi selanjutnya ${ }^{2}$.

Tetapi apakah untuk mencapai tujuan mulia itu kita sebagai orang tua dan para pendidik sudah mengetahui metode dan juga sarana apa yang perlu kita persiapkan. Konsep pendidikan Islam yang bagaimana yang dibutuhkan oleh para orang tua dan juga para pendidik untuk mencetak generasi muslim yang shalih dan mushlih.

\footnotetext{
${ }^{1}$ Sir Percy Nann, salah seorang pendidikan BArat terkemuka; dalam sebuah makalah terbitan Da'irah Al-Ma'arif Al-Brithaniyyah.

2 Thariq Al-Bina' At-Tarbawi Al-Islami, Dr. Ajil Jasim An-NAsymi, hlm. 114-115
} 
Dr. Muhammad Muhammad Badri merupakan seorang dosen dalam bidang ilmu psikologi dan parenting anak, beliau berasal dari Mesir dan menjadi seorang pengajar di salah satu universitas terbaik di kota Kairo. ${ }^{3}$ Dr. Muhammad Muhammad Badri membuat suatu konsep Pendidikan Islam yang didasarkan pada pengalaman para pendidik, pendahulu termasuk konsep yang diajarkan Rasulullah saw dalam mendidik anak. Konsep yang terhimpun dalam huruf-huruf yang menyusun frase Human Touch yang akan kita dalami lebih lanjutMaka dapat saya rumuskan suatu rumusan masalah dalam penulisan jurnal ini yaitu "Bagaimana Konsep Pendidikan Islam Human Touch menurut Dr. Muhammad Muhammad Badri. Adapun tujuan penulisan artikel ini adalah untuk mengetahui bagaimana konsep pendidikan Islam "Human Touch" menurut Dr. Muhammad Muhammad Badri.

\section{Kajian Pustaka}

Berbagai pengertian konsep dikemukan oleh beberapa pakar. Konsep didefinisikan sebagai suatu arti yang mewakili sejumlah objek yang mempunyai ciri-ciri yang sama. Konsep diartikan juga sebagai suatu abstraksi dari ciri-ciri sesuatu yang mempermudah komunikasi antar manusia dan memungkinkan manusia untuk berpikir ${ }^{3}$.

Menurut Kamus Besar Bahasa Indonesia Pendidikan adalah proses pengubahan sikap dan tata laku seseorang atau kelompok orang dalam usaha mendewasakan manusia melalui upaya pengajaran dan pelatihan; proses, cara dan pembuatan mendidik.

Menurut Etimologi ( Bahasa ) Pendidikan dalam Islam : Dalam Bahasa Arab Pendidikan : berasal dari kata Tarbiyah, dengan kata kerja Rabba yang memiliki makna mendidik atau mengasuh. Jadi Pendidikan dalam Islam adalah Bimbingan oleh pendidik terhadap perkembangan jasmani, rohani dan akal anak didik sehingga bisa terbentuk pribadi muslim yang baik.

Sedangkan tujuan pendidikan akan menentukan kearah mana anak didik akan dibawa. Disamping itu pendidikan berfungsi untuk mengembangkan kemampuan serta meningkatkan mutu kehidupan dan martabat manusia indonesia. Tujuan pendidikan dapat dilihat dari dua sudut pandang yaitu menurut Islam dan tujuan pendidikan secara umum.

Tujuan Pendidikan Secara Religi: 1. Pembinaan Akhlak, 2. Penguasaan Ilmu, 3. Keterampilan bekerja dalam masyarakat, 4. Mengembangkan akal dan Akhlak, 5. Pengajaran Kebudayaan, 6. Pembentukan kepribadian 
Tujuan Pendidikan nasional menurut TAP MPR NO II/MPR/1993 yaitu Meningkatkan kualitas manusia Indonesia, yaitu manusia yang beriman dan bertakwa terhadap Tuhan Yang Maha Esa, berbudi pekerti luhur, berkepribadian, mandiri, maju, tangguh, cerdas, kreatif, terampil, berdisiplin, beretos kerja profesional serta sehat jasmani dan rohani.

Konsep Pendidikan Islam

\section{Pengertian Pendidikan Islam}

Zuhairini dalam bukunya Filsafat Pendidikan Islam mengemukakan bahwa "pendidikan Islam adalah usaha yang diarahkan kepada pembentukan kepribadian anak sesuai dengan ajaran Islam atau sesuatu upaya dengan ajaran Islam, memikir, merumuskan dan berbuat berdasarkan nilai-nilai Islam, serta bertanggung jawab sesuai dengan nilai-nilai Islam. Dapat diuraikan bahwa konsepsi pendidikan model Islam, paradigma Islam tidak hanya pada sebagai upaya pencerdasan semata, tetapi juga penghambaan diri kepada Tuhannya. Di dalam Al-Qur"an dan Hadits sebagai sumber utama ajaran Islam dapat ditemukan kata-kata atau istilah-istilah yang pengertiannya terkait dengan pendidikan, yaitu rabba, allama, dan addaba. ${ }^{4}$

Ahmad Marimba seperti yang dikutip oleh Nur Uhbiyati, mengemukakan dua macam tujuan pendidikan Islam yaitu tujuan sementara dan tujuan akhir. Tujuan sementara adalah sasaran sementara yang harus dicapai oleh umat Islam yang melaksakan pendidikan Islam. Tujuan sementara disini yaitu tercapainya berbagai kemampuan seperti kecakapan jasmaniah pengetahuan membaca, pengetahuan menulis, ilmu-ilmu kemasyarakatan, kesusilaan, keagamaan, kedewasaan, jasmani dan rohani, dan sebagainya. b.Tujuan akhir Tujuan akhir pendidikan Islam yaitu terwujudnya kepribadian Muslim yaitu kepribadian yang seluruh aspekaspek merealisasikan atau mencerminkan ajaran Islam ${ }^{5}$.

Dasar pendidikan Islam yaitu Alquran dan hadis Nabi saw yang merupakan sumber pokok ajaran Islam. Prinsip pendidikan Islam juga ditegakkan atas dasar yang sama dan berpangkal dari pandangan Islam

\footnotetext{
${ }^{4}$ Achmadi, Ideologi Pendidikan Islam, (Yogyakarta: Pustaka Pelajar, 2005), h. 24

5 Nur Uhbiyati, Ilmu Pendidikan Islam. (Bandung: Pustaka Setia, 1996), h.3
} 
secara filosofis terhadap jagat raya, masyarakat, ilmu, pengetahuan, dan akhlak. Menurut Abudin Nata, prinsip-prinsip pendidikan Agama Islam yaitu sebagai berikut: ${ }^{6}$

a. Sesuai dengan fitrah manusia

b. Keseimbangan:

c. Sesuai dengan keadaan zaman dan tempat

d. Tidak menyusahkan manusia

e. Sesuai dengan perkembangan ilmu pengetahuan dan teknologi.

f. Berorientasi pada masa depan: ${ }^{7}$

g. Kesederajatan

h. Keadilan, persaudaraan, musyawarah dan keterbukaan

Menurut Nur Uhbiyati Dalam pendidikan Islam, metode yang dapat digunakan diantaranya yaitu melalui metode teladan, nasehat, hukuman, cerita, kebiasaan, menyalurkan bakat, dan melalui peristiwa-peristiwa ${ }^{8}$.

\section{Pembahasan}

Tidak perlu disangsikan lagi bahwa pendidikan Islam merupakan seni yang mesti ditekuni oleh para oramgtua dan pendidik. Sudah barang tentu, penekunan tersebut meliputi tujuan-tujuan pendidikan, srana-sarananya, lingkungan sekitar seorang pendidik, dan sisi-sisi psikologis dan mental seorang anak didik ${ }^{9}$.

Selain itu, tidak perlu diragukan lagi bahwa kepustakaan Islam teramat kaya akanbuku, makalah, dan kajian teoritis yang menonjolkan etikaetika pendidikan anak ala Islam, namun sangat miskin akan sisi pengalaman praktis yang menjelaskan bagaimana para pendidik memperlakukan anakanak mereka dengan etika-etika tersebut. Padahal, sisi ini perlu diperkaya agar pendidikan Islam tidak sekedar slogan yang diulang-ulang dan ditulis dalam buku-buku tanpa penerapan ataupun praktik nyata; agar kita keluar dari bingkai penulisan sistem-sistem pendidikan menuju pengalaman yang lebih kongret dalam menerapkannya.

\footnotetext{
6 Abudin Nata, Studi Islam Komprehensip ( Jakarta: Kencana, 2011), h. 50

7 Ibid.., h. 65

8 Uhbiyati, Ilmu pendidikan Islam..., h. 134-140)

${ }^{9}$ Muhammad Muhammad Badri, Sentuhan Jiwa untuk Anak Kita (Bekasi: Daun Publishing) hlm. 2
} 
Dr. Muhammad Muhammad Badri mengangkat kajian ini dari sudut pandang pengalaman mendidik anak-anaknya sendiri, sehingga prnsipprinsip pendidikan yang beliau tuangkan bukanlah sekedar prinsip-prinsip literatur(hasil membaca), melainkan prinsip-prinsip realitayang merupakan hasil pengumulan dengan aneka masalah kehidupan ${ }^{10}$.

Sekilas pandang seni berinterkasi dengan anak merupakan hasil dari kajian dan studi kepustakaan pelbagai buku pendidikan sekaligus petikan dari pengalaman pribadi Dr. Muhammad Muhammad Badri dalam mendidik buah hati tercinta. Beliau memberi nama konsep pendidikan anak ini dengan Human Touch (sentuhan manusiawi) karena beliau merasa kita sangat membutuhkan sentuhan manusiawi nan lembut dalam berinteraksi dengan putra putri kita ${ }^{11}$.

Konsep pendidikan anak yang terhimpun dalam huruf-huruf yang menyusun frase Human Touch adalah:

$\mathrm{H}=$ Hear him; dengarkan ia

$\mathrm{U}=$ Understand his feelings; mengertilah perasaannya

$\mathrm{M}=$ Motivate his desire; berilah hasratnya motivasi

$\mathrm{A}=$ Appreciate his efforts; berilah apresiasi atas usahanya

$\mathrm{N}=$ News him; berilah ia informasi

$\mathrm{T}=$ Train him; latihlah ia

$\mathrm{O}=$ Open his eyes; bukalah matanya

$\mathrm{U}=$ Understand his uniqueness; pahamilah keunikannya

$\mathrm{C}=$ Contact him; jalinlah hubungan dengannya

$\mathrm{H}=$ Honour him; hargailah ia ${ }^{12}$.

Penulis akan membahas konsep diatas satu persatu sesuai dengan apa yang dituliskan oleh Dr. Muhammad Muhammad Badri dalam bukunya yang berjudul "Sentuhan Jiwa untuk Anak Kita".

\footnotetext{
${ }^{10}$ Ibid....hlm 3

${ }^{11}$ Ibid hlm 10

${ }^{12}$ Ibid...... hlm. 20
} 


\section{Hear Him}

Manusia manapun ketika orang lain mendengarkannya, pastilah ia menyukai orang lain itu tatkala ketiadaan orang yang mendengarkannya nyaris membuatnya putus asa. Maka, tatkala Anda mendengarkan anak Anda dengan seksama, bertambahlah kedekatannya dengan Anda, dan cintanya kepada Anda ${ }^{13}$.

Apabila Anda ingin-wahai orang tua- menyentuh dan meraih hati anak anda, Anda sangat perlu menyelinap ke dalam akal si anak untuk mengungkap apa yang ia inginkan. Cukup dengarkanlah baik-baik perkataan si anak, niscaya Anda mengetahui apa yang ia inginkan dan mereka idamidamkan, bahkan mungkin lebih baik daripada yang bisa ia ungkapkan. ${ }^{14}$

Mendengarkan anak bukanlah sekedar tidak memotong pembicaraan mereka, melainkan juga mendengarkan dengan senang hati sampai akhir pembicaraan, tanpa berkeinginan kuat untuk menjawab seolah-olah kitasedang adu balap dengan anak dalam berbicara! Jika Anda belum memiliki kemahiran ini, mulailah melatihnya dari sekarang, melalui; 1. mendengarkan dengan penuh kesabaran, 2. Menjadikan anak sebagai pusat perhatian, 3. Belajar bersabar, 4 . Benar-benar mementingkan anak ${ }^{15}$.

Selain bisa menjadi pendengar yang baik bagi anak, dialog antara orang tua dan anak amatlah penting. Dialog menghargai kepribadian manusia dalam diri anak, sehingga yang diperhatikan bukan hanya gagasan dan pengalaman orang tua, tetapi pengalaman itu dibiarkan tumbuh bersama pencarian anak itu sendiri melalui diskusi ${ }^{16}$. Dialog memiliki banyak jalur, antara lain; pengajaran, keterlibatan emosional, negosiasi, perintah/larangan, dan motivasi ${ }^{17}$.

\section{Understand His Feelings}

Keagungan yang sebenarnya dalam mendidik anak-anak kita adalah berinteraksi dengan mereka seraya mengenyangkan semangat berempati

\footnotetext{
13 Ibid........ hlm.39

${ }_{14}$ Yauman li Al-Hushul ‘ala Al-Quwwah wa As-Sulthah fi Ta'amulika ma'a Al-Akharin, James K.....,hlm. 110

${ }^{15}$ Muhammad Muhammad Badri, Sentuhan Jiwa untuk Anak Kita (Bekasi: Daun Publishing) hlm. $45-46$

${ }^{16}$ Ibid...hlm 65

${ }^{17}$ Ibid....hlm 66
} 
dengan perasaan mereka; mengasiani kelemahan, kekurangan, dan kesalahan mereka, serta kegemaran yang sejati dalam mengoreksi kesalahan mereka sambil menjaga perasaan mereka, dengan cara melimpahkan rasa iba atas kesalahan mereka, dan cinta yang hakiki kepada mereka. Juga, memberi perhatian pada apa yang sedang mereka perhatikan dan mereka pikirkan.

Komando hakiki bagi anak-anak adalah komando hati, bukan komando fisik; komando kesukarelaan, bukan komando tekanan; komando cinta, bukan komando teror. Pun, kita tidak akan meraih yang terbaik dari anak-anak kita jika kita belum membuat hati mereka cenderung sehingga mencintai kita. Sebab, apabila mereka mencintai kita niscaya mereka mematuhi kita. Kenapa? Karena akal tidak bisa mendengar sebelum hati mendengar ${ }^{18}$.

Ketahuilah, jika memang kita tidak ingin rasa cinta antara kita dan anak-anak akan sirna, yang kita butuhkan adalah memahami perasaan mereka. Cintailah mereka walau bagaiman pun keadaan mereka. Arahkanlah perilaku mereka ke arah yang benar tanpa merendahkan harga diri mereka. Dampingilah mereka untuk memberi kekuatan kepada mereka. Terimalah kekuatan anak-anak kita apa adanya. Terimalah perbuatan terbaik yang mereka lakukan, dan maafkanlah kesalahan-kesalahan mereka. Jadilah orang tua yang baik dan lakukanlah segalanya dengan cinta. ${ }^{19}$

\section{Motivate His Desire}

Berbagai contoh nyata dalam berinterkasi dengan anak-anak dapat diketahui bahwa sangatlah penting bagi kita untuk mewujudkan "motivasi positif" untuk anak-anak kita dan juga "harapan positif" atas perbaikan perilaku mereka. Hal itu perlu dilakukan karena tindakan orang tua atau pendidik yang menunjukkan adanya harapan positif kepada anak akan memberi dampak positif bagi perkembangan jiwa anak. Bahkan, berbagai penelitian ilmiah yang dilakukan menyatakan bahwa hal itu berpengaruh untuk memotivasi anak memperbaiki diri.

Anggapan anak terhadap dirinya sendiri sebenarnya muncul dari cara Anda berinteraksi dengannya. Sebagai contoh, apa yang dilakukan Isa Alaihissalam inilah cara terbaik untuk melihat perilaku anak-anak, yaitu

\footnotetext{
18 Ibid...hlm 133

${ }^{19}$ Ibid....hlm 135
} 
dengan memusatkan perhatian pada hal-hal positif, atau mencari hal-hal positif daripada menaruh perhatian pada hal-hal negatif (jika ada) ${ }^{20}$.

Maka, kita semua juga harus mencari tahu apa kiranya keistimewaan anak-anak kita dan apa saja bakat serta sifat-sifat baik mereka, untuk kemudian kita berkonsentrasi pada semua itu agar terus berkembang.

Semua itu dapat kita lakukan dengan memberi motivasi dan dukungan kepada anak-anak kita, juga melalui berbagai julukan positif yang sesuai dengan keistimewaan masing-masing anak, sehingga mengingatkan anak yang bersangkutan akan kelebihan yang dimilikinya, untuk kemudian ia kembangkan.

\section{Appreciate His Efforts}

Dulu, metode yang dipakai Rasulullah saw untuk memberi apresiasi adalah setiap kali beliau berbicara dengan siapapun, beliau selalu menghadap ke arah orang yang beliau ajak bicara dengan seluruh tubuh beliau sehingga semua orang, termasuk para anak-anak merasa bahwa mereka diperhatikan Rasul sebagaimana halnya para sahabat dewasa.

Oleh sebab itu, setiap pendidik-termasuk para ayah dan ibu tentunyadituntut untuk memperhatikan beberapa poin berikut ini:

1. Tidak melontarkan kritik secara frontal terhadap kesalahan yang dilakukan anak.

2. Memilih waktu dan tempat yang tepat untuk menyampaikan teguran.

3. Tidak kehilangan kontrol emosi di saat menyampaikan teguran.

4. Memulai semua dengan pujian dn apresiasi yang tulus.

5. Jika kesalahan yang dilakukan anak harus diganjar dengan hukuman maka Anda harus memastikan bahwa hukuman yang diberikan kepadanya memang benar-benar sepadan dengan kesalahan yang ia lakukan. Selain itu Anda juga harus selalu ingat sebuah kaidah yang menyatakan bahwa tujuan sejati dari hukuman adalah untuk perbaikan, bukan sebagai pembalasan dendam. 
6. Memuji prestasi anak meski sekecil apapun juga. ${ }^{21}$

\section{News Him}

Agar kondisi anak-anak kita di masa kini tidak seperti kondisi kita di masa lalu, dan agar kondisi mereka di masa depan tidak seperti kondisi kita di masa kii, sudah seharusnyalah jika pengalaman yang kita miliki tidak habis hanya sebatas apa yang kita alami saat ini, tetapi seharusnya kita berusaha membuat anak-anak kita memiliki pengalaman yang jauh lebih banyak dari yang kita miliki. Caranya dalah dengan mendidik mereka untuk menghadapi setiap peristiwa yang mereka alami.

Jadi sebenarnya, semua cerita tentang pengalaman kita yang kita sampaikan kepada anak-anak kita harus dapat membuat mereka mencari cara memecahkan masalah yang lebih baik daripada cara yang kita gunakan di masa lalu ${ }^{22}$.

Dari penjelasan inilah kita dapat mengetahui betapa pentingnya cerita tentang kehidupan yang disampaikan orang tua atau pendidik kepada anak, termasuk cerita tentang kesulitan yang pernah dihadapi serta cara memecahkan kesulitan tersebut, untuk membentuk salah satu corak pendidikan yang disampaikan melalui kejadian dalam kehidupan, berbagai pengalaman yang dijalani sendiri oleh orang tua, berbagai pandangan hidup orang tua, dan pengetahuan mendalam orang tua atas masyarakat di sekitarya $^{23}$.

\section{Train Him}

Jika Anda ingin menjadikan anak Anda sebagai pribadi yang mampu menghadapi semua kenyataan dalam kehidupan, sanggup menghadapai berbagai tantangan berat yang ada di kedalaman samuderanya, maka Anda harus melatih anak Anda itu untuk memikul tanggung jawabnya sendiri. Sebab kemampuan untuk memikul tanggung jawab itulah yang mengembangkan kepribadiannya sehingga ia tidak akan mudah merasa takut

\footnotetext{
${ }^{21}$ Muhammad Muhammad Badri, Sentuhan Jiwa untuk Anak Kita (Bekasi: Daun Publishing) hlm. 282-284

22 Ibid...hlm 223

${ }^{23}$ Ibid...hlm 234
} 
terhadap kegagalan dan tumbuh menjadi sosok yang siap menghadapi semua aral yang merintang ${ }^{24}$.

Sebagai contoh, kita dapat memberi kebebasan kepada anak-anak dalam memilih atau memberi barang, kita juga dapat meminta anak-anak kita yang sudah mulai remaja untuk ikut mengurus urusan rumah tangga. Contohnya dengan mengajaknya urun pendapat atas suatu permasalahan yang sedang terjadi. Atau dapat pula kita. Para ayah, meminta anak kita yang sudah mulai remaja untuk mewakili kita dalam menyelesaikan urusan tertentu.

Dengan cara-cara seperti yang disebutkan diatas, kita dapat meraih dua tujuan dengan satu kesempatan, yaitu: pertama, kita dapat membebaskan anak-anak kita dari belenggun psikologis yang mengekang anak kita, yaitu perasaaanya bahwa ia tidak pernah kita akui sebagai anak yang sudah besar; kedua, kita dapat melatih anak dengan berbagai masalah yang ada didalamnya. Tidak perlu diragukan lagi, tindakan seperti ini pasti akan menumbuhkembangkan kepribadian anak melalui kesematan yang diberikan kepadanya untuk terjun langsung ke tengah masyarakat ${ }^{25}$.

\section{Open His Eyes}

Hal terpenting dalam hal pendidikan anak adalah kita harus menyakini bahwa urgensi pendidikan bukanlah menduplikasikan watak dan perilaku kita pada anak didik. Akan tetapi, urgensi pendidikan adalah pengembangan berbagai rencana dan persiapan dirinya untuk mampu menjalani hidup ini dengan semurna, baik secara moriil maupun materiil, seperti menjalankan ibadah kepada allah SWT dengan benar dan memberikan tauladan akhlak mulia kepada seluruh manusia di segenap penjuru muka bumi $^{26}$.

Akidah membagun akhlak pikiran, akhlak jiwa dan akhlak perilaku dalam jati diri seorang anak. Untuk itu, metode pendidikan yang benar bermula dengan penanaman sapek akidah dalam hati anak, sehingga hal ini mengerucut pada pembentukan akhlaknya. ${ }^{27}$

${ }^{24}$ Ibid...hlm. 421

25 Manhaj At-Tarbiyah Al-Islamiyah, Muhammad Quthb, jilid 2, hlm.205)

${ }^{26}$ Muhammad Muhammad Badri, Sentuhan Jiwa untuk Anak Kita (Bekasi: Daun Publishing) hlm. 505

27 Al-Ummah Al-Islamiyah min At-Tab'iyyah ila Ar-Riyadah, Pasal: At-Tarbiyah Asy-Syamilah 
Hendaklah para pendidik memandang penting untuk menghidupkan pengaruh-pengaruh keimanan yang terkandung dalam asma' dan sifat-sifat Allah SWT melalui berbagai aktifitas hati, seperti rasa cinta dan benci, rasa takut dan harap, rasa senang dan takut, rasa berserah dan khusyu' dalam diri si anak. Sehingga, tertanamlah keyakinan dalam hatinya, bahwa kehidupan hanya berarti dengan aqidah yang benar. $^{28}$

\section{Understanding His Uniqueness}

Keunikan setiap manusia telah ditegaskan dalam hadits Rasulullah saw, "Allah SWT menciptakan Adam dari seluruh jenis tanah, sebagian dari tanah yang lembut, keras, putih dan hitam."

Dari hadits di atas jelaslah perbedaan-perbedaan tabiat antar individu tergantung komposisi tanah darimana ia diciptakan.

Maka dari itu sesorang pendidik yang cerdas harus memperhatikan perbedaan-perbedaan individu antara anak-anaknya. Sebagaimana diwasiatkan Ibnu Maskawaihi, "Hendaknya engkau memperhatikan perilaku anak-anak dan kesiapan mereka untuk menerima atau meninggalkan sebuah adab, sebagian mereka ada yang kurang rasa malu, ada juga yang sangat pemalu, ada yang dermawan, pelit, pengasih, kasar, iri, dan berbagai tingkatan sifat. Mereka berbeda dalam menerima nilai-nilai yang mulia. Anda sebagai pendidik harus memahami bahwa mereka tidak sama. Ada yang mudah menerima, ada yang sulit, pertengahan dan berbagai tingkatan yang tidak terhitung jumlahnya." ${ }^{29}$

Pendidikan yang baik dengan tidak berusaha membuat anak-anak Anda sebagai duplikat Anda. Jangan membawa mereka melihat satu perkara dengan satu sisi pandang. Jangan memaksa mereka melakukan perintahperintah. Seorang pendidik yang sukses adalah yang membuka ruang untuk perbedaan kepribadian, perilaku dan pemikiran serta perbedaan ambisi seorang anak bukan duplikat saudara, orang tua, atau pun gurunya. Tetapi ia adalah individu tersendiri. ${ }^{30}$

\section{Contact Him}

\footnotetext{
${ }^{28}$ Muhammad Muhammad Badri, Sentuhan Jiwa untuk Anak Kita (Bekasi: Daun Publishing) hlm. 509 29 Siyasah Tarbawiyah Khathi'ah, Muhammad Dimas, hlm.31

${ }^{30}$ Muhammad Muhammad Badri, Sentuhan Jiwa untuk Anak Kita (Bekasi: Daun Publishing) hlm. 694
} 
Tidak diragukan lagi bahwa keluarga membutuhkan komunikasi yang intens antara anggota-anggotanya. Komunikasi ini yang menjaga keluargasetelah takwa kepada Allah-dari sekularisme.

Kedekatan pendidik dengan anak didiknya akan terwujud dengan meluangkan waktu untuk mendangarkan keluhan, kesulitan dan keinginan mereka.

Semua itu adalah faktor penting dalam berinteraksi dengan anak-anak. Wilson Woods menemukan bahwa penerimaan anak-anak terhadap diri guru dan keterbukaan mereka sangat erat kaitannya dengan keberadaan, kehadiran, dan kesiapan guru tersebut dalam menerima para murid, lalu menghabiskan waktu bersama mereka ${ }^{31}$.

Seperti tokoh pendidikan yang pertama yaitu Rasulullah saw yang selalu menyediakan waktu untuk para sahabatnya, di masjid, di pasar, atau di jalan. Jika beliau tidak ada, mereka pergi ke rumah beliau. Beliau menyambut dan mengajari mereka dan menjawab pertanyaan-pertanyaan mereka. Rasulullah saw tidak pernah mencegah atau menolak tamu, bahkan beliau selalu tersenyum kepada mereka. ${ }^{32}$

Kebersamaan bersama anak-anak bisa dilakukan dengan duduk makan bersama, pergi berkunjung bersama, melewati momen istimewa bersama, pergi bertamasya dan berinteraksi bersama, juga duduk bersama sehari-hari $^{33}$.

\section{Honour Him}

Sebelum dilahirkan pun, bayi sudah tergolong"anak-anak Adam", sementara Allah telah memuliakan anak-anak Adam; "Dan sesungguhnya telah Kami muliakan anak-anak Adam." (Al-Isra' : 70). Maka, kita mesti memuliakan anak dan benar-benar mengakui bahwa dirinya terhormat. Kita pun mesti menghormati "kemanusiaan" dalam diri anak.

Kepribadian yang kokoh dan kepercayaan diri anak adalah salah satu hal terpenting yang harus diwujudkan dan salah satu kewajiban pendidikan orang tua. Syarat pertama dalam pendidikan itu adalah mengoreksi cara pandang orang tua kepada anak mereka. Ia adalah manusia mungil; manusia

\footnotetext{
${ }^{31}$ Ibid...hlm. 700

${ }^{32}$ Muhammad Muhammad Badri, Sentuhan Jiwa untuk Anak Kita (Bekasi: Daun Publishing) hlm. 701

${ }^{33}$ Ibid...hlm. 716
} 
yang masih lemah; manusia yang memiliki fitrah yang membuatnya awas terhadap banyak hal. Kalau begitu, nasihat pendidikannya adalah: Muliakanlah anak dan tumbuhkanlah dalam dirinya rasa percaya diri.

Salah satu cara memuliakannya adalah dengan memberinya julukan yang bagus, sesuai dengan kemampuan dan keistimewaannya. Misalnya, pendidik menyebut anak dengan julukan: "Sang Pemberani", "Si Sabar", "Sang Penemu", "Sang Juara", "Si Jujur", atau "Si Terpercaya". semua julukan itu harus sesuai dengan perangainya yang disukai. Rasulullah saw pun telah melakukan hal itu terhadap para sahabatnya Radhiyallahu Anhum; beliau menjuluki Abu Bakar sebagai Ash-Shiddiq (Sang Selalu Percaya); Umar sebagi Al-Faruq (Sang Pembela); Khalid sebagai Saifullah Al-Maslul (Sang Pedang Allah yang Terhunus); dan Abu Ubaidah sebagai Al-Amin (Sang Terpercaya). ${ }^{34}$

\section{SIMPULAN}

Dari pembahasan di atas dapat disimpulkan bahwa konsep pendidikan Islam Human Touch menurut Muhammad Muhammad Badri menekankan pada pendidikan yang bukan hanya sekedar teoritis atau bersumber kepada berbagai buku-buku pendidikan saja, tetapi lebih ditekankan kepada tataran pengalaman para pendidik terdahulu, utamanya sang pendidik utama yaitu Rasulullah saw dan pengalaman beliau sendiri dalam mewujudkan generasi Islam yang sholeh dan mushlih. Yang tentu saja berbagai pengalaman ini memberikan gambaran yang jelas dalam menghadapi berbagai persoalan pendidikan anak. Konsep Human Touch mengajarkan kepada kita bahwa berinteraksi dengan buah hati memerlukan seni tersendiri. Seni yang dimaksud dalam Human Touch ini adalah kita pandai mendengarkan anak-anak; mengerti perassan mereka; memotivasi hasrat mereka; menghargai usha mereka; memberi mereka informasi yang berguna; melatih mereka bersikap positif; membuka mata mereka tentang kehidupan ini; memahami keunikan mereka; menjalin hubungan dengan mereka; dan tidak pelit memuji mereka.

\footnotetext{
${ }^{34}$ Ibid...hlm 770 - 772
} 


\section{DAFTAR PUSTAKA}

Achmadi. 2005. Ideologi Pendidikan Islam. Yogyakarta: Pustaka Pelajar.

Ahmad D. Marimba. 1989. Pengantar Filsafat Pendidikan Islam.Bandung: Al-Ma'arif

Al-Jamaly, Muhammad Fadhil. 1977. Nahwa Tarbiyat Mukminat.

Al-Ummah Al-Islamiyah min At-Tab'iyyah ila Ar-Riyadah, Pasal: At-Tarbiyah Asy-Syamilah.

An-Nughaimsyi, Abdul Aziz. Ilm An-Nafs Ad-Da'wa.

Badri, Muhammad Muhammad. 2018. Sentuhan Jiwa untuk Anak Kita. Bekasi: Daun Publishing.

Bakkar, Abdul Karim. Muqaddimat li An-Nuhudh bi Al-Amal Ad-Da'wi.

Dimas, Muhammad. Siyasah Tarbawiyah Khathi'ah.

Nata, Abudin. 2005. Filsafat Pendidikan Islam. Jakarta: Gaya Media Pratama

Nata, Abudin. 2011. Studi Islam Komprehensip. Jakarta: Kencana

Qaradhawi, Yusuf. Tsaqafah Ad-Da'iyah.

Quthb, Muhmmad. Manhaj At-Tarbiyah Al-Islamiyah Jilid 2.

Soekidjo Notoatmodjo. $2003: 16$

Thalib, Hisyam. Dalil At-Tadrib Al-Qiyadi.

Uhbiyati, Nur. 1996. Ilmu Pendidikan Islam. Bandung: Pustaka Setia 
Usman, Akram Mishbah. Thariqah li Tashma' min Ibnika Rajulan Fadzdzan.

Zulkarnain. 2008. Transformasi Nilai-Nilai Pendidikan Islam. Yogyakarta: Pustaka Pelajar 